\title{
Retinal detachment and its relation to cataract surgery
}

\author{
R H GRAY; A R EVANS, I J CONSTABLE, ANd I L McAllister \\ From The Lions Eye Institute, 2 Verdun Street, Nedlands, Perth 6009, Western Australia.
}

SUMmaRy In Western Australia during the period 1 January 1976 to 31 December 19871089 eyes of 1044 patients in hospital were operated upon for primary rhegmatogenous retinal detachment due to causes other than penetrating trauma. Of these eyes 295 (27\%) were aphakic or pseudophakic. During this period the annual number of cataract operations in the State increased by a factor of $245 \%$, while aphakic and pseudophakic retinal detachment operations rose by only $55 \%$. The declining risk of retinal detachment following cataract surgery is attributed to improvements in microsurgical techniques. In 1983 and 1984 the incidence of aphakic and pseudophakic retinal detachments dropped significantly $(\mathrm{p}<0 \cdot 05)$. At about this time extracapsular cataract surgery became widespread in the State, and this may explain the observed fall in retinal detachment operations. Since 1984 the incidence has risen owing to the rapidly increasing prevalence of pseudophakia in the resident population.

Recent studies have shown the incidence of retinal detachment (RD) to vary from 8 to 13 per 100000 of the population. ${ }^{1-5}$ Aphakic retinal detachment constitutes approximately one-quarter of these..$^{5-8}$

With the advent of microsurgical techniques and the introduction of extracapsular surgery postoperative complications such as RD may have declined, though it is well recognised that surgical or YAG laser posterior capsulotomy increases the risk. . $^{-11}$ This study was undertaken to determine what effect the changing pattern of cataract surgery in Western Australia (WA) has had on the overall incidence of $\mathrm{RD}$ in this State.

The remote WA population provided a good model for this study because all rhegmatogenous RDs within the State were referred to a small number of surgeons (and hospitals) in Perth and Bunbury, and their records were traceable. By excluding outof-State referrals we believe that the figures are accurate for the resident WA population over the period studied.

\section{Material and methods}

Available data on all patients undergoing surgery for primary RD in the period 1 January 1976 to 31 December 1987 were obtained from hospital records for all centres equipped to carry out this

Correspondence to Dr R H Gray. operation in the State. RDs that followed penetrating trauma were excluded, as were patients not resident in WA at the time of surgery.

The following information was obtained on each patient: age, sex, side affected, date and type of previous cataract surgery, date of posterior capsulotomy, and date of primary RD surgery. Figures for the total number of cataract operations each year were obtained from the Health Department of WA and population figures were obtained from the Federal Bureau of Statistics. The data obtained were analysed by Student's $t$ test.

\section{Results}

Between 1976 and 1987 the WA population rose steadily from 1.17 million to 1.50 million, an increase of $28 \%$. During the same period the number of cataract operations per year increased from 1089 to 3755 , a rise of $245 \%$. Over the same 12 years 1089 eyes of 1044 patients underwent primary RD surgery as defined above (Table 1). Information could not be obtained on a further 13 eyes, which were excluded from the study. Two hundred and ninety-five eyes were aphakic or pseudophakic $(27.7 \%)$ and 794 were phakic $(72 \cdot 3 \%)$. Intracapsular extractions (ICCE) had been performed on all eyes presenting in 1976, while by 1987 the proportion had fallen to $40 \%$, the remaining eyes having undergone extracapsular surgery (ECCE) (Fig. 1). 
Table 1 State population (State pop) in millions, total cataract operations, primary retinal detachment operations and calculated retinal detachment incidence ( $R D$ incidence) for aphakic and phakic patients, 1976-87.

\begin{tabular}{|c|c|c|c|c|c|}
\hline \multirow[t]{2}{*}{ Year } & \multirow[t]{2}{*}{ State Pop. } & \multirow{2}{*}{$\begin{array}{l}\text { Cataract } \\
\text { operations }\end{array}$} & \multicolumn{3}{|c|}{ Primary $R D R D$ Incidence } \\
\hline & & & & Phakic & Aphakic \\
\hline 1976 & $1 \cdot 17$ & 1089 & 74 & $4 \cdot 35$ & 1.79 \\
\hline 1977 & $1 \cdot 20$ & 1127 & 76 & $5 \cdot 25$ & 0.91 \\
\hline 1978 & $1 \cdot 22$ & 1209 & 77 & $4 \cdot 10$ & 1.96 \\
\hline 1979 & $1 \cdot 24$ & 1310 & 79 & $4 \cdot 35$ & 1.85 \\
\hline 1980 & $1 \cdot 27$ & 1361 & 95 & 5.59 & $1 \cdot 73$ \\
\hline 1981 & $1 \cdot 30$ & 1597 & 83 & $3 \cdot 84$ & $2 \cdot 38$ \\
\hline 1982 & $1 \cdot 34$ & 1968 & 114 & $5 \cdot 82$ & $2 \cdot 60$ \\
\hline 1983 & $1 \cdot 36$ & 2419 & 55 & $3 \cdot 28$ & 0.66 \\
\hline 1984 & $1 \cdot 38$ & 2708 & 71 & 3.69 & $1 \cdot 30$ \\
\hline 1985 & 1.41 & 3015 & 107 & $5 \cdot 24$ & $2 \cdot 26$ \\
\hline 1986 & 1.46 & 3221 & 127 & 6.09 & $2 \cdot 60$ \\
\hline 1987 & $1 \cdot 50$ & 3755 & 131 & $6 \cdot 30$ & $2 \cdot 80$ \\
\hline
\end{tabular}

Of the 1044 patients 438 were female ( $42 \%$ ). RD operations were carried out on 577 right eyes (53\%). Bilateral RD surgery was carried out on 45 patients (4.3\%). Aphakic/pseudophakic patients presented most commonly between the ages of 61 and 80 years, while phakic patients were usually 51-70 years, though a small peak was observed in the 21-30-year group.

Of the 218 eyes with RD that had undergone ICCE data on cataract and RD surgery dates were obtained for 209. RD surgery took place within one year in 82 of these (38\%) (Fig. 2). Of the 49 eyes that had undergone ECCE without subsequent capsulotomy 26 had RD surgery within one year (53\%) (Fig. 3).
RD surgery was carried out on 28 eyes that had undergone ECCE and delayed Nd-YAG capsulotomy, and $19(68 \%)$ of these were within one year of the capsulotomy (Fig. 4).

The average frequency of RD in the State was 6.7 per 100000 population per year (4.82 for phakic patients and 1.88 for aphakic/pseudophakic patients). In 1983 the incidence of aphakic/pseudophakic RDs fell to $0 \cdot 66$, and in 1984 it was $1 \cdot 3$. In the following years the incidence rose again (Fig. 5). When 1983 and 1984 were compared with the years before and since, the observed fall was statistically significant $(\mathrm{p}<0.05)$.

When the number of RD procedures performed on aphakic/pseudophakic eyes each year was compared with the number of cataract operations in the preceding year, the average risk of RD during 1976-82 was $1.75 \%$ (SD 0.4 ), while during $1983-7$ it fell to $0 \cdot 86 \%$ (SD 0.31) (Fig. 6).

\section{Discussion}

While the number of cataract operations per year has increased dramatically between 1976 and 1987 in this State, by a factor of $245 \%$, the incidence of aphakic/ pseudophakic RD has risen by only $55 \%$ ( 1.8 per 100000 in 1976 rising to $2 \cdot 8$ in 1987).

The age distribution of our patients is similar to that of other studies, ${ }^{2312}$ as is the slightly higher incidence of RD surgery on the right eyes of both phakic and aphakic/pseudophakic patients. ${ }^{258}$. The $4 \cdot 1 \%$ incidence of bilaterally affected eyes is similar to that found in a previous study ${ }^{3}$ but lower than that in a larger study by Ashrafzadeh et $a l^{12}$ who found the
Fig. 1 The yearly numbers of primary retinal detachment operations for 295 eyes that underwent intracapsular $(\Theta)$ or extracapsular surgery (-).

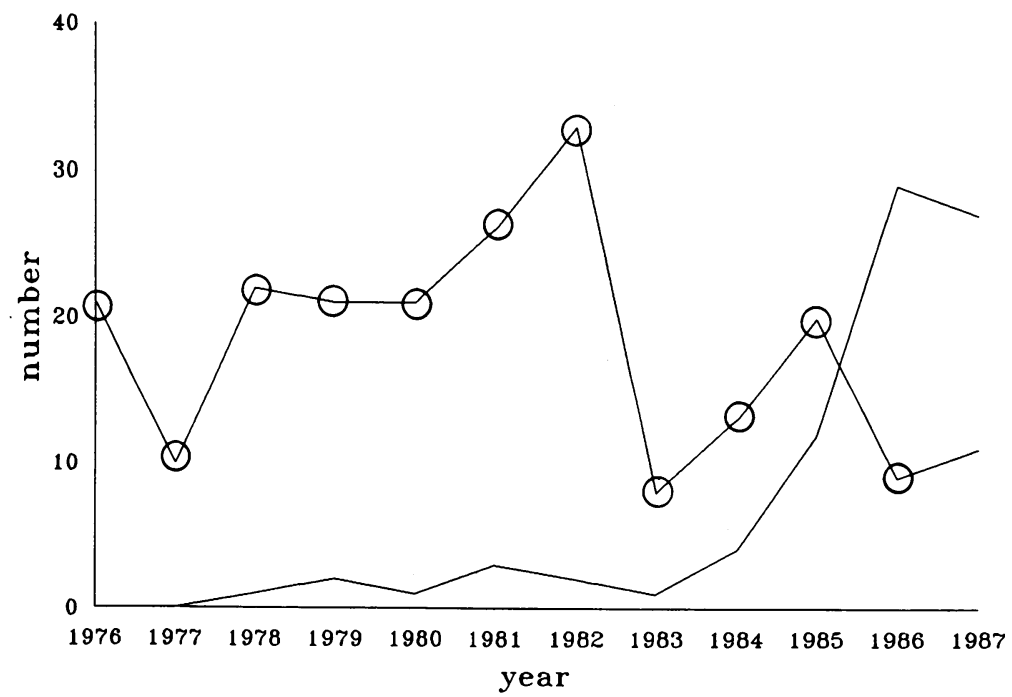




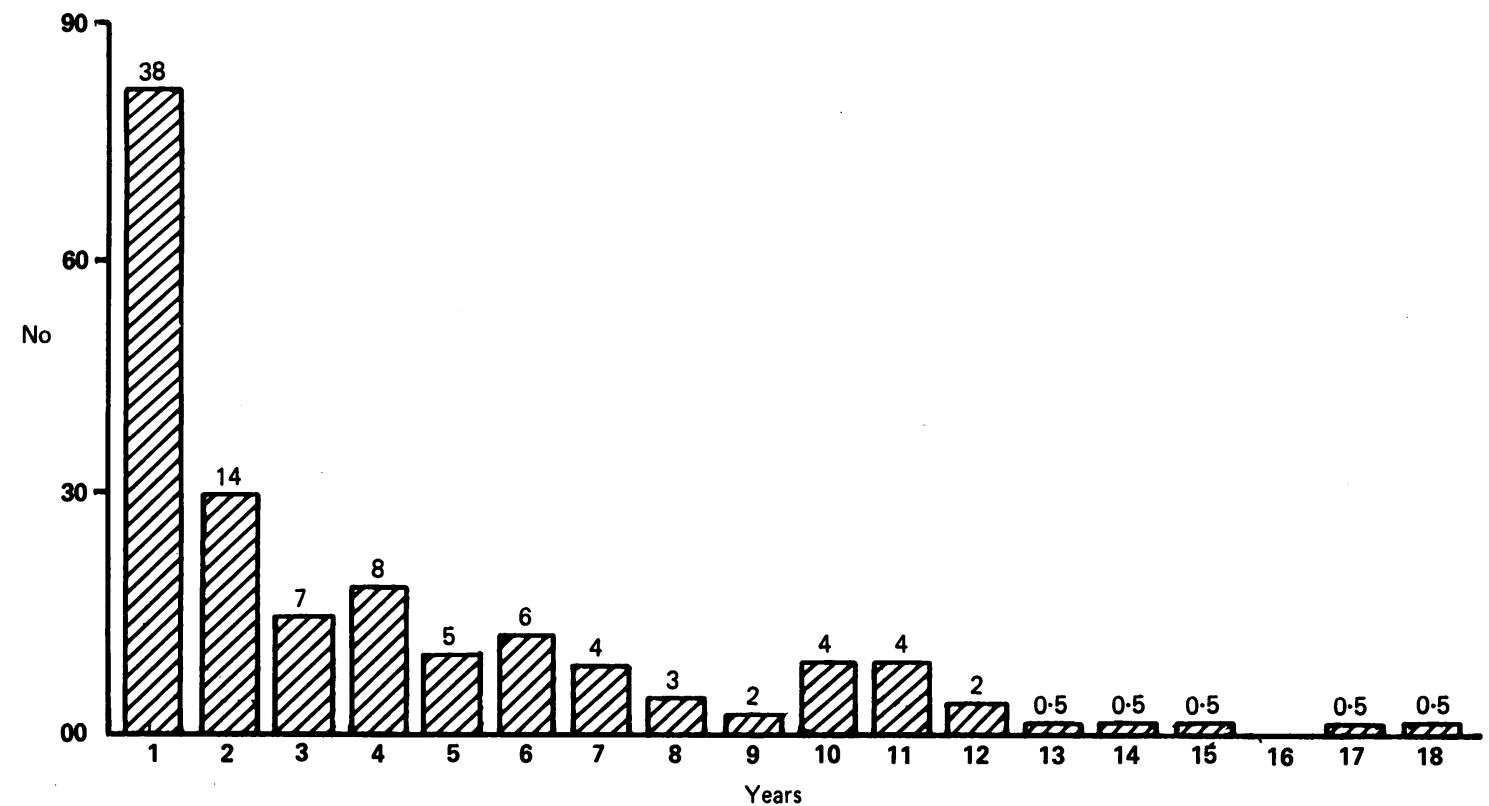

Fig. 2 Time interval to retinal detachment surgery for 209 eyes from the date of intracapsular cataract surgery (\% of total above each bar).

incidence of bilaterally affected eyes to be $36 \cdot 8 \%$ for aphakic and $31 \cdot 2 \%$ for phakic eyes. This much higher figure may be partly explained by their inclusion of subclinical cases.

Our figures have shown that the risk of RD following cataract surgery is maximal in the first year, this being true for both ICCE and ECCE groups. This similarity has been reported elsewhere..$^{13-15}$ In a post-mortem study of aphakic and pseudophakic human eyes Osterlin found ${ }^{16}$ a significant deficit of hyaluronic acid only in those eyes operated upon by the intracapsular technique. The increased liquefaction of vitreous gel that this causes was thought by Binkhorst ${ }^{17}$ to be a significant factor in the causation of RD. But the striking similarity between ICCE and ECCE in terms of the interval to detachment, found in this and other studies, argues against the importance of this factor.

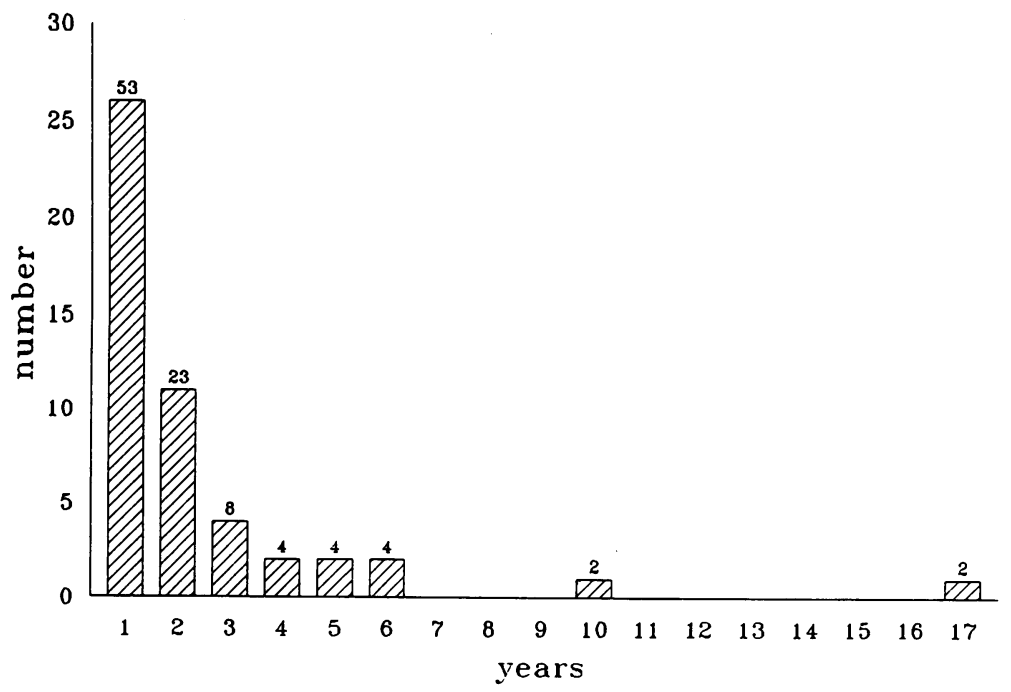

Fig. 3 Time interval to retinal detachment surgery from the date of cataract surgery for 49 eyes that underwent extracapsular extraction without subsequent posterior capsulotomy (\% of total above each bar). 
Fig. 4 Time interval to retinal detachment surgery from the date of $\mathrm{Nd}$-YAG capsulotomy for 28 eyes following extracapsular cataract surgery ( $\%$ of total above each bar).

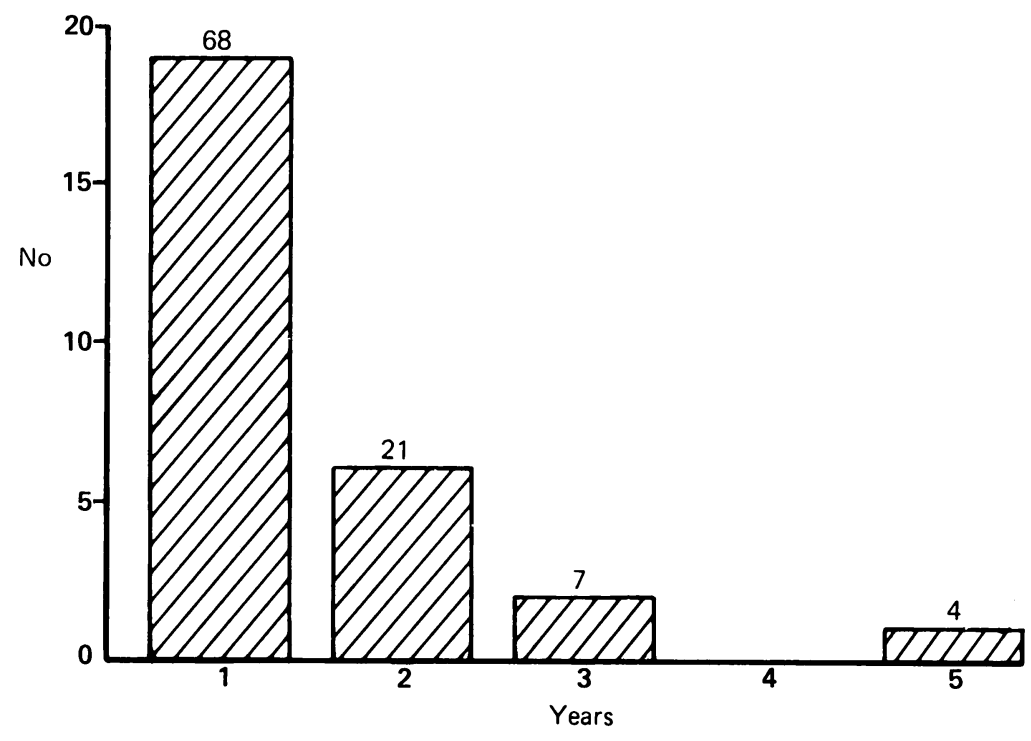

Of the 79 eyes that had RD surgery following extracapsular surgery in our group $28 \mathrm{had}$ a posterior capsulotomy present $(36 \%)$. As expected, most RDs following this procedure occurred within one year, in agreement with a previous study. ${ }^{18}$ We have no accurate figures for the number of Nd-YAG laser procedures carried out during the study period and cannot therefore comment on the risk of RD from this procedure, but three large studies ${ }^{9119}$ have found the incidence of RD following YAG capsulotomy to be $0.5 \%, 1 \%$, and $2 \%$ respectively. The importance of posterior capsulotomy, whether primary or delayed, surgical or laser, is further evident from the $3.6 \%$ RD risk reported by Wilkinson et al on 1500 eyes that underwent ECCE with phacoemulsification.2" Posterior capsulotomies were carried out on $94.7 \%$ of these eyes, and the authors comment on the similarity of this group to cases of intracapsular aphakia. We attribute the slightly higher risk of aphakic/pseudophakic RD since 1983 in our study to increasing availability and use of the Nd-YAG laser.

The average frequency of RD during the study period was 6.7 per 100000 population per year
Fig. 5 Incidence of retinal detachment, per 100000 of population, for phakic patients (-) and aphakic/ pseudophakic patients

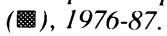

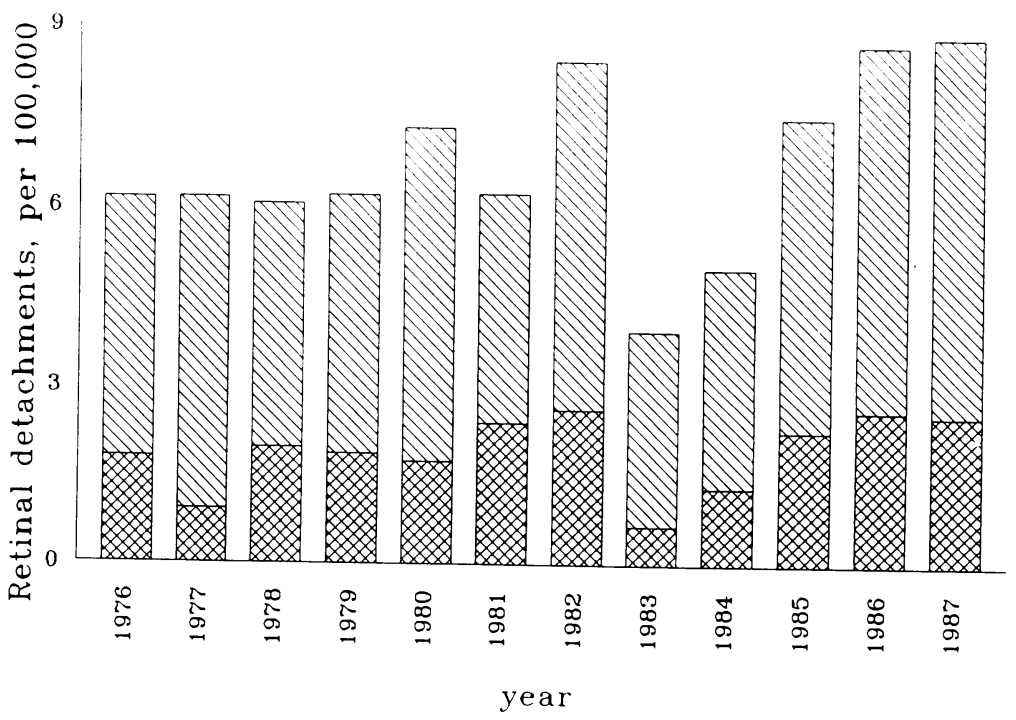




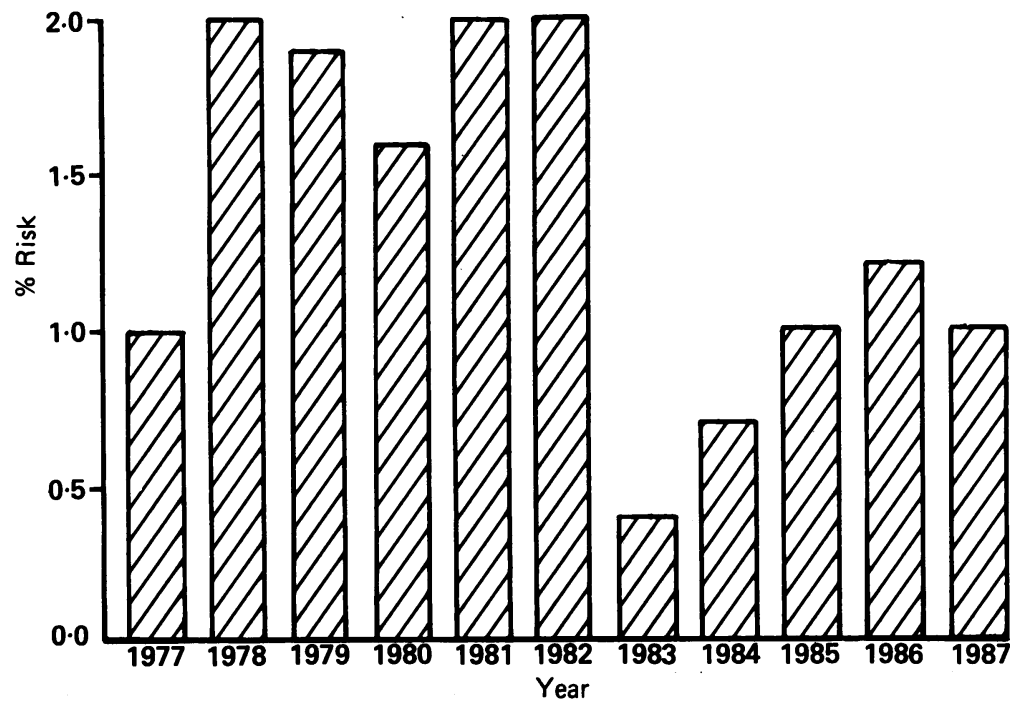

Fig. 6 Calculated risk of retinal detachment following cataract surgery, 1977-87.

This figure is broadly similar to those of other studies, ${ }^{235}$ and some of the differences may be attributable to the varying prevalence of aphakia, and possibly myopia, in the populations studied.

Between 1982 and 1983 almost all cataract surgeons in this State changed to extracapsular surgery, and a statistically significant fall in aphakic and pseudophakic RDs followed this change. We believe this provides good evidence that extracapsular surgery protects against $R D$ when compared with ICCE. In a comparison of RD risk for 122 myopic eyes that underwent ICCE, with 151 eyes undergoing ECCE (both without vitreous loss) Jaffe $e t a^{1}$ found the risk in the former group to be $5.74 \%$ and in the latter only $0 \cdot 66 \%$. Minimum follow-up was one year. Coonan $e t$ al studied 842 consecutive ECCEs with a minimum follow-up of one year and found the overall risk of RD to be $1.4 \% .{ }^{13}$ In uncomplicated cases in which the posterior capsule was left intact the risk was only $0 \cdot 8 \%$. In another study of 3065 cases of ECCE the risk was $1.7 \%$, with a minimum follow-up of one year. ${ }^{14}$ Hurite et al studied 2095 patients who underwent ECCE by phacoemulsification, and the overall risk was $1.6 \%$, with minimum follow-up of one year. ${ }^{22}$ The risk was only $1.2 \%$ for those cases in which the posterior capsule was left intact.

Accurate assessment of the risk of RD following cataract surgery is dependent on prolonged follow-up of a defined population. Such was not the case in this study. Nevertheless, bearing in mind that most RDs occur within the first two years, we believe our comparison of the number of aphakic/pseudophakic RDs per year with the total number of cataract operations for the previous year to be valid. The risk of RD over the study period has fallen from a mean of $1.75 \%$ in the early part of the study to a mean of $0.86 \%$ in the years since 1982 . At least some of this reduction is due to improved microsurgical techniques, and in particular the avoidance of vitreous loss. Though this retrospective study had not yielded reliable data on vitreous loss, other studies have confirmed it's importance. ${ }^{132022}$

This study has documented the incidence of primary retinal detachment surgery during a period of major change in the surgical management of cataract. We have shown that the number of RD operations has risen much less than the number of cataract operations, and we attribute this to improvements in microsurgical techniques. The statistically significant fall in the number of aphakic/pseudophakic RD operations which began in 1983 may be attributable to the introduction of extracapsular cataract surgery a short time before.

We are grateful for the assistance of Dr Valerie Alder for statistical analysis of the data.

\section{References}

1 Michaelson IC, Stein R (co-ordinators), Barkai S et al. A study in the prevention of retinal detachment. Ann Ophthalmol. 1969; 1: 45-9.

2. Haimann M, Burton TC, Brown CK. Epidemiology of retinal detachment. Arch Ophthalmol 1982; 100: 289-92.

3 Wilkes SR, Beard CM, Kurland LT, Robertson DM, O'Fallon WM. The incidence of retinal detachment in Rochester Minnesota, 1970-78. Am J Ophthalmol 1982; 94: 670-3.

4 Haut J, Massin M. Frequency of retinal detachment in the French population. Arch Ophtalmol (Paris) 1975; 35: 533-6.

5 Laatikanien L, Tolppanen EM, Harjo H. Epidemiology of rhegmatogenous retinal detachment in a Finnish population. Acta Ophthalmol (Kbh) 1985; 63: 59-64. 
6 Schepens CL. Retinal detachment and aphakia. Arch Ophthalmol 1951; 45: 1-16.

7 Norton EWD. Retinal detachment in aphakia. Am J Ophthalmol 1964; 58: 111-24.

8 Everett WG, Katzin D. Meridional distribution of retinal breaks in aphakic retinal detachment. AM J Ophthalmol 1968; 66: 928-32.

9 Ficker LA, Vickers S, Capon MRC, Mellerio J, Cooling RJ. Retinal detachment following Nd YAG laser posterior capsulotomy. Eye 1987; 1: 86-9.

10 Leff SR, Welch CJ, Tasman W. Rhegmatogenous retinal detachment after YAG laser posterior capsulotomy. Opthalmology 1987; 94: 1222-5.

11 Shah GR, Gills JP, Durham DG, Asmus WH. 3000 YAG lasers in posterior capsulotomies: an analysis of complications and comparison to polishing and surgical discission. Ophthalmic Surg 1987; 17: 473-77.

12 Ashrafzadeh T, Schepens CL, Elzeneiny IJ, Moura R, Morse P, Kraushar MF. Aphakic and phakic retinal detachment. Arch Ophthalmol 1973; 89: 476-83.

13 Coonan P, Fung WE, Webster LG, Allen AW, Abbott RL. Incidence of retinal detachment following extracapsular cataract extraction. Ophthalmology 1985; 92: 1096-101.

14 Smith PW, Stark WJ, Maumenee AE, et al. Retinal detachment after extracapsular cataract extraction with posterior chamber intraocular lens. Ophthalmology 1987; 94: 495-504.
15 Cousins S, Boniuk I, Okun E, et al. Pseudophakic retinal detachments in the presence of various IOL types. Ophthalmology 1986; 93: 1198-208.

16 Osterlin S. Changes in the macromolecular composition of the vitreous produced by removal of the lens. Proceedings of the $2 / \mathrm{st}$ International Congress, Mexico, DF 1970. Excerpta Medica International Congress Series 222: 1620-3.

17 Binkhorst CD. Corneal and retinal complications after cataract extracion. Ophthalmology 1980; 87: 609-17.

18 McPherson AR, O'Malley RE, Bravo J. Retinal detachment following late posterior capsulotomy. Am J Ophthalmol 1983; 95: 593-7.

19 Stark WJ, Worthen D, Holladay JT, Murray G. Nd YAG lasers: an FDA report. Ophthalmology 1985; 92: 209-12.

20 Wilkinson CP. Anderson LS, Litte JH. Retinal detachment following phaco-emulsification. Ophthalmology 1978: 85: 151-6.

21 Jaffe NS, Clayman HM, Jaffe MS. Retinal detachment in myopic eyes after intracapsular and extracapsular cataract extraction. Am J Ophthalmol 1984; 97: 48-52.

22 Hurite FC, Sorr EM, Everett WG. The incidence of retinal detachment following phaco-emulsification. Ophthalmology 1979; 86: 2004-6.

Accepted for publication 12 May 1989. 